\title{
Modeling of the microstructural evolution and lifetime prediction of MCrAIX coatings on Nickel based superalloys in high temperature oxidation
}

Kang Yuan, Robert Eriksson, Ru Peng, Xin-Hai Li, Sten Johansson and Yandong Wang

\author{
Linköping University Post Print
}

\section{Tweet}

N.B.: When citing this work, cite the original article.

Original Publication:

Kang Yuan, Robert Eriksson, Ru Peng, Xin-Hai Li, Sten Johansson and Yandong Wang, Modeling of the microstructural evolution and lifetime prediction of MCrAlX coatings on Nickel based superalloys in high temperature oxidation, 2013, Surface and Coatings Technology, (232), 15, 204-215.

http://dx.doi.org/10.1016/j.surfcoat.2013.05.008

Copyright: Elsevier http://www.elsevier.com/

Postprint available at: Linköping University Electronic Press

http://urn.kb.se/resolve?urn=urn:nbn:se:liu:diva-90013 


\title{
Modeling of microstructural evolution and lifetime prediction of MCrAIY coatings on Nickel based superalloys during high temperature oxidation
}

\author{
Kang Yuan ${ }^{1,}{ }^{*}$, Robert Eriksson ${ }^{1}$, Ru Lin Peng ${ }^{1}$, Xin-Hai Li $^{2}$, Sten Johansson ${ }^{1}$, Yan-Dong \\ Wang $^{3}$ \\ ${ }^{I}$ Department of Management and Engineering, Linköping University, SE-58183 Linköping, Sweden \\ ${ }^{2}$ Siemens Industrial Turbomachinery AB, SE-61283 Finspång, Sweden \\ ${ }^{3}$ University of Science and Technology, Beijing 100083, China \\ "Corresponding author. E-mail: kang.yuan@liu.se, Tel.: +4613281784
}

\begin{abstract}
MCrAlY coatings are deposited onto superalloys to provide oxidation and corrosion protection at high temperature by the formation of a thermally grown oxide scale. In this project, the oxidation behaviour of a HVOF CoNiCrAlYSi coating on IN792 was studied for both isothermal oxidation (900, 1000 and $\left.1100{ }^{\circ} \mathrm{C}\right)$ and thermal cycling $\left(100-1100{ }^{\circ} \mathrm{C}\right)$. The microstructural evolution of the CoNiCrAlYSi coatings after oxidation was investigated. It was found that the Al-rich $\beta$ phase is gradually consumed due to two effects: surface oxidation and coating-substrate interdiffusion. Some voids and oxides along the coating-substrate interface, or inside the coating, were considered to play a role in blocking the diffusion of alloying elements. Based on the microstructural observation, an oxidation-diffusion model, considering both surface oxidation and coating-substrate interdiffusion, was developed by using Matlab and DICTRA software to predict the useful life of MCrAlY coatings. A new concept of diffusion blocking is also introduced into the model to give more accurate description on the microstructural evolution. The results from modeling and the experimentally established composition profiles showed good agreement.
\end{abstract}

Keywords: MCrAlY coating; HVOF; Life prediction; Interdiffusion; Oxidation; Diffusion blocking

\section{Introduction}


The combustor and turbine sections of gas turbines offer harsh environments for structural parts and the materials for such applications need to withstand considerable oxidation and corrosion [1]. Resistance against oxidation and corrosion is achieved by the in-situ formation of a protective oxide layer on the surface of the alloy [2]. At high temperatures, alumina is the oxide which provides the best protection and high-temperature oxidation resistant alloys are consequently alumina formers [2]. Superalloys - developed with mainly mechanical properties (such as creep resistance) in mind - may not have the prerequisites to form a protective oxide layer [3,4]. Hence, the need arises for protective coatings which ensure the formation of a protective oxide layer and act as an $\mathrm{Al}$ reservoir so that alumina can be reformed would it crack and spall due to thermal cycling [3,5,6].

Overlay coatings have gained usage both as stand-alone protective coatings and as bond coats in thermal barrier coating (TBC) systems $[1,4,7]$. Common processes for overlay coating deposition are: vacuum plasma spraying (VPS), atmospheric plasma spraying (APS), high-velocity oxy-fuel (HVOF) spraying, low-pressure plasma spraying (LPPS) and electron beam physical vapor deposition (EBPVD) $[1,3,8,9]$. The former two produce coatings with a characteristic splat-on-splat structure. Different oxidation and diffusion behaviours have been reported depending on the deposition process [10,11]. Overlay coatings are chosen from the MCrAlY family of alloys where $\mathrm{M}$ is either of Ni, Co and $\mathrm{Fe}$, or a combination thereof, $\mathrm{Y}$ is added to improve the scale adhesion $[4,7]$ while other beneficial minor elements are also added such as $\mathrm{Si}$, Ta, $\mathrm{Hf}$ and $\mathrm{Zr}[3,4,7,12]$. The microstructure of MCrAlY coatings includes, most prominently, the $\gamma^{-}, \gamma^{\prime}$ - and $\beta$-phases, the former being solid-solution-Ni and the latter two aluminides, $\mathrm{Ni}_{3} \mathrm{Al}$ and $\mathrm{NiAl}$ respectively $[5,13,14]$. Other phases, present in some MCrAlY alloys, are $\alpha-C r$ and $\sigma-\operatorname{CoCr}[13,14]$.

As oxidation resistance is achieved by the formation of alumina, the useful life of the coating is often determined by the $\mathrm{Al}$ depletion that occurs through oxidation and interdiffusion [3,5,6,15-17]. The removal of $\mathrm{Al}$ from the coating results in the dissolution of the $\beta$-phase, thus giving rise to $\beta$ depleted zones at the coating surface, due to oxidation, and at the coating-substrate interface, due to interdiffusion $[6,15,16]$. When the $\beta$-phase is completely depleted, or when the Al concentration reaches a critically low value, the coating can no longer work as an $\mathrm{Al}$ reservoir and less-protective oxides forms $[2,6,13,15-17]$; the depletion of aluminum thus marks the end of the useful life of the 
coating [3]. The modeling and prediction of $\mathrm{Al}$ depletion through mechanisms of oxidation and interdiffusion thus becomes important for 1) the durability assessment of existing coatings, 2) establishing of appropriate substrate/coating couples, and 3) the development of new coating alloys.

Earlier work on modeling of $\mathrm{Al}$ depletion in coatings includes Nesbitt and Heckel [12] who modeled the oxidation of a NiCrAlZr coating on a Ni-base substrate. The model was usable for short thermal exposure but failed to predict $\mathrm{Al}$ concentration during the later stages of the coating life. A more complex oxidation model was devised by Nijdam et al. [18] who predicted concentration profiles in a NiCrAl alloy taking into account oxidation of all included metal components with applying varying oxidation kinetics. The modeled concentration profiles showed reasonable agreement with experimental data.

Modeling which also includes interdiffusion has been performed by several researchers. Nesbitt and Heckel [19] modeled the $\beta$ phase depletion due to interdiffusion in $\gamma / \gamma+\beta$ diffusion couples chosen from the NiCrAl system. Taylor et al. [5] modeled the oxidation and interdiffusion of $\mathrm{Al}$ in $\mathrm{NiCrAl}$ alloys. The presented model failed to accurately predict the $\mathrm{Al}$ concentration profile in the interdiffusion zone. Renusch et al. [17] predicted the life of a NiCoCrAlY coating used as bond coat in a TBC system by modeling oxidation and interdiffusion; the interdiffusion constant was experimentally determined for the substrate/coating couple of interest. Lee et al. [15] devised a model for predicting the $\beta$ phase depletion in a CoCrAlY coating by oxidation and interdiffusion. Their results showed the significant influence by the $\mathrm{Al}$ diffusivity or oxidation rate on the $\beta$-phase depletion, indicating that the highly accurate database of elemental diffusivities and oxidation mechanisms is required.

More recently, the Thermo-Calc and DICTRA software have made more advanced models possible. Recent attempts to utilize Thermo-Calc and DICTRA for such purposes include Nijdam and Sloof [20] who modeled the $\beta$-depletion due to isothermal and cyclic oxidation of a freestanding MCrAlY. Beck et al. [16] modeled coating-substrate interdiffusion for NiCoCrAlY coatings; the model was said to be "semi-quantitative" and usable mainly for microstructures low in $\gamma^{\prime}$ and $\beta$. Hald et al. [21] modeled the interdiffusion for an MCrAlY coating; diffusion was only modeled to occur in the $\gamma$ matrix phase. The lack of diffusion data for $\gamma^{\prime}$ and $\beta$ has previously been troublesome. Hald et al. 
[21] circumvented this by a "labyrinth factor" which took into account the impeded diffusion due to phases other than $\gamma$.

The model development of $\mathrm{Al}$, or $\beta$-phase, depletion is progressing; the Thermo-Calc [22] and DICTRA [23] software show promising results when used for such purposes. Earlier attempts have suffered from the limitations of lacking diffusivity data or have not fully implemented a coupled interdiffusion-oxidation model. The research presented in this paper therefore aims at developing a DICTRA-based Al depletion model for overlay coatings, taking both oxidation and interdiffusion into account. The model formulation was based on microstructural studies of HVOF MCrAlY coatings oxidized isothermally at $900-1100{ }^{\circ} \mathrm{C}$ and cyclically at $1100{ }^{\circ} \mathrm{C}$.

\section{Materials and Experiments}

The studied specimens had a disk shape with $20 \mathrm{~mm}$ diameter and a thickness of 3-5 mm. The substrate was made from cast nickel based polycrystalline superalloy Inconel 792 (IN792). The substrate surface was machined and grit blasted (by $\mathrm{Al}_{2} \mathrm{O}_{3}$ grit) prior to coating deposition. The CoNiCrAlYSi coating, $\sim 200 \mu \mathrm{m}$ thick, was deposited onto one surface of the substrate by highvelocity oxy-fuel spraying (HVOF). The nominal compositions of the substrate and coating are listed in Table 1. After coating deposition, the specimens were all solution heat treated at $1120{ }^{\circ} \mathrm{C}$ for $2 \mathrm{~h}$ in vacuum and then aged at $845{ }^{\circ} \mathrm{C}$ for $12 \mathrm{~h}$ in air. The heat treatment achieved both $\gamma^{\prime}$ precipitation for the substrate and strengthened the bonding between the coating and the substrate.

Four oxidation tests were carried out: 1) $100-1100{ }^{\circ} \mathrm{C}$ thermal cycling exposure (TCF-1100 $\left.{ }^{\circ} \mathrm{C}\right), 2$ ) $1100{ }^{\circ} \mathrm{C}$ isothermal exposure (iso- $1100{ }^{\circ} \mathrm{C}$ ), 3) $1000{ }^{\circ} \mathrm{C}$ isothermal exposure (iso- $1000{ }^{\circ} \mathrm{C}$ ) and 4) 900 ${ }^{\circ} \mathrm{C}$ isothermal exposure (iso- $900{ }^{\circ} \mathrm{C}$ ). For the thermal cycling exposure, one cycle includes $1 \mathrm{~h}$ at 1100 ${ }^{\circ} \mathrm{C}$ in air, followed by $\sim 10$ min cooling with compressed air which gives a minimum temperature of $100{ }^{\circ} \mathrm{C}$. Specimens were removed from the furnaces at predetermined times as shown in Table 2. Each temperature and time in Table 2 corresponds to one specimen. A specimen that had only gone through initial heat treatment was used as reference. 
The microstructure of the specimens was characterized by optical microscopy and by a fieldemission gun scanning electron microscope (SEM) with X-ray energy dispersive spectroscopy (EDS). The SEM images can be obtained from secondary electrons (SE) and back-scattered electrons (BSE) where the former is more sensitive to the specimen surface and the latter to atomic number. The electron source will be given for each SEM image in the following sections.

\section{Modeling Procedure}

The procedure of oxidation-diffusion model is described in Fig. 1, aiming to simulate the diffusion process and corresponding microstructure evolution due to coating-substrate interdiffusion, surface oxidation and diffusion-blocking effect.

In the model, the diffusion simulation was done with the DICTRA software by using the homogenization model $[24,25]$ with the advanced Ni-base thermodynamic and kinetic databases TCNI5 and MONI2 [26] developed by the Thermo-Calc Software company. The homogenization model is suitable for multiphase simulations, assuming that local equilibrium takes places at each node. Fourteen homogenization models are supplied by the DICTRA software [23], which are based on different assumptions about phase distribution and can be chosen for interdiffusion simulation in accordance with the microstructure in the sample. In this study, all homogenization models were tried and evaluated to find a suitable one for the subsequent oxidation-diffusion modeling. Several phases were included in the simulation: $\gamma, \gamma^{\prime}, \alpha, \beta$ and $\sigma$.

$\mathrm{Al}$ depletion near the coating surface due to oxidation was introduced by removing oxidized $\mathrm{Al}$ from the near-surface area using the Matlab software. The oxidation was simply modeled as

$$
h=\left(K_{p} t\right)^{\frac{1}{2}}
$$

where $h$ is the oxide scale thickness and $K_{p}$ is the parabolic oxidation constant. In this study, only growth of an alumina scale was considered during simulations. To obtain the value of $K_{p}$ at the different temperatures, the thickness of the alumina was measured on the oxidized specimens. Since 
the coating surface was quite rough, the oxide thickness was obtained by image analysis as the area of the alumina oxide in a SEM image divided by the image width. This approach works well for isothermal exposure but fails to capture the actual $\mathrm{Al}$ consumption in the thermal cycling process due to the heavy scale spallation.

In this model the diffusion blocking effect was also included, by modifying the simulating diffusion times, rather than changing the diffusion coefficients, in the coating and substrate. For instance a stronger blocking effect was implemented by a shorter time for diffusion. As shown in Fig. 1 the coating-substrate couple was represented by a number of nodes, for which the composition was stored. The simulation was performed as an iterative process where each iteration involved: 1) DICTRA simulation of diffusion in the substrate for time $t_{l}, 2$ ) Al removal from the outermost nodes (i.e. lowering $\mathrm{Al}$ concentration in these nodes by Matlab) corresponding to oxidation for time $t_{1}$ or $t_{2}$, whichever the longest, 3) DICTRA simulation of diffusion in the coating for time $t_{2}, 4$ ) Al removal from the outermost nodes corresponding to oxidation for time $t_{3}$, 5) DICTRA simulation of interdiffusion for time $t_{3}$. The new composition profile from each step was applied into the following new steps. The total oxidation time (time increment) for each iteration hence was $t_{3}+\max \left(t_{1}, t_{2}\right)$; this time increment was adapted to the oxidation rate so that $t_{3}+\max \left(t_{1}, t_{2}\right)$ was small during the faster initial oxidation and increased towards the end of the simulation where the oxidation rate was low. The time increments were chosen from the $1-20 \mathrm{~h}$ interval. The input composition for the simulation was taken from EDS measurements from the heat-treated specimen. The effect of diffusion blocking (by pores and internal oxides) was controlled by the relative length of the three diffusion times: $t_{1}, t_{2}$ and $t_{3}$. In this paper, no diffusion blocking in the substrate is considered, which yields $t_{1} \geq t_{2}$.

Two blocking factors were defined to describe the diffusion blocking that occurred internally in the coating, $P_{I}$ which was the fraction of blocked diffusion time in the coating (Eq.2) and in the coatingsubstrate interface, $P_{2}$ which was the fraction of blocked diffusion time at the interface (Eq.3).

$$
P_{1}=\frac{\text { blocked diffusion time in the coating }}{\text { total diffusion time in the process }}=\frac{t_{1}-t_{2}}{t_{1}+t_{3}}
$$




$$
P_{2}=\frac{\text { blocked diffusion time at the interface }}{\text { total diffusion time in the process }}=\frac{t_{1}}{t_{1}+t_{3}}
$$

If $P_{l}=0$ and $P_{2}=0$, no diffusion blocking is included. The existence of diffusion blocking structures in the studied specimens requires that $P_{1}, P_{2}>0$ in the modeling performed here. Larger values of $P_{1}$ and $P_{2}$ give stronger diffusion blocking.

A microstructural interpretation of the blocking parameters would be that $P_{1}$ is related to internal oxidation along splat interfaces in the coating while $P_{2}$ is related to alumina and voids at the coatingsubstrate interface. However, the relation between the blocking parameters and microstructural constituents may not be trivial since not only physical effects but also chemical interactions needs to be considered. For instance, $P_{2}$ should depend on, but is not necessarily equal to, the area fraction of particles and voids at the coating-substrate interface.

\section{Results and Discussion}

\subsection{Microstructural analysis}

\subsubsection{Initial heat treatment}

The typical microstructure in the superalloy (the substrate) is shown in Fig. 2(a); the constituents were precipitates of large primary and small secondary $\gamma^{\prime}\left(\mathrm{FCC}, \mathrm{L}_{2}\right)$ in a $\gamma(\mathrm{FCC}$, disordered) matrix, and $(\mathrm{Ti}, \mathrm{Ta})$-rich and $(\mathrm{Cr}, \mathrm{Mo})$-rich carbides along grain boundaries. (Ti,Ta)-rich carbides were present inside grains as well, were large and had a blocky shape. Larson et al. [25] also observed such constituents in IN792.

Fig. 2(b) shows the calculated phases in the IN792 substrate at various temperatures. The calculation was performed with the Thermo-Calc software and the composition used was $\mathrm{Ni}-12.5 \mathrm{Cr}$ 9Co-4.175W-4.175Ta-3.975Ti-3.375Al-1.9Mo-0.08C (wt.\%). The calculation gives an indication of what microstructure can be expected in practice. For instance, more $\gamma^{\prime}$ precipitates form at lower 
temperatures and (Ti,Ta)-rich MC carbides form during solidification (around $1320{ }^{\circ} \mathrm{C}$ ) as also observed by others [27-29]. Some other phases $((\mathrm{Cr}, \mathrm{W})$-rich $\mu,(\mathrm{Co}, \mathrm{W})$-rich $\mathrm{HCP})$ were also predicted, but not detected by SEM analysis. It should be noted that, at lower temperatures, microstructural changes may be sluggish; one example is that the thermodynamically unstable MC carbides should have dissolved at the aging temperature (i.e. $845^{\circ} \mathrm{C}$ ) but they were observed after the aging treatment.

The microstructure of the $\sim 200 \mu \mathrm{m}$ thick CoNiCrAlYSi coating after the initial solution and aging heat treatment is shown in Fig. 3(a); the corresponding composition profile is presented in Fig. 3(b) where the position of the coating-substrate interface is taken as distance $=0$. Obviously, interdiffusion between the coating and the substrate had occurred during the heat-treatment. The rough surface of the coating had oxidized slightly forming a thin oxide scale as shown in Fig. 3(c). According to the EDS results, the surface oxides consisted predominantly of $\mathrm{Al}_{2} \mathrm{O}_{3}$, which was probably of the stable type $\alpha$ $\mathrm{Al}_{2} \mathrm{O}_{3}$; the formation of $\alpha-\mathrm{Al}_{2} \mathrm{O}_{3}$ during the HVOF process has been reported by other researches [30,31]. Due to the surface oxidation, the $\mathrm{Al}$ content in the coating decreased and a $\beta$-depleted zone was formed, see Fig. 3(c). The thickness increase of the $\beta$-depleted zone during isothermal or thermal cycling exposure reflects the progress of surface oxidation which will be discussed in detail in the next section. Some voids and oxides were found in the material, seen as dark areas in Fig. 3(a). The oxides in the substrate-coating interface were $\mathrm{Al}_{2} \mathrm{O}_{3}$ which probably came from the grit blasting process prior to coating deposition or first layer spraying.

Recrystallized $\gamma$ grains with fine $\gamma^{\prime}$ precipitates were observed in the substrate beneath the coatingsubstrate interface as shown in Fig. 3(d). The stored elastic energy from the machining and/or grit blasting processes should be the driving force for such recrystallization. In addition, some small, dispersed (Ti,Ta)-rich MC carbides were found in the substrate, which probably formed through the dissolution of the original large carbides followed by re-precipitation.

Y-rich particles, which may be Y-oxides [31,32], were detected along the interfaces between splats (Fig. 3(e)). Internal oxidation is common in APS coatings where the trapped oxygen from the coating deposition process forms stable oxides by reacting with elements of high oxygen affinity, such as yttrium and aluminum [33]. The oxidation of $\mathrm{Y}$, and partially oxidation of $\mathrm{Al}$, during $\mathrm{HVOF}$ deposition was also reported by Brandl [34] who observed a slower diffusion rate in HVOF coatings 
deposited from pre-oxidized powders. Voids and oxides in the coating, or along the coating-substrate interface, can be considered as obstacles for diffusion. The diffusion blocking effect by a void/oxide structure was considered by Evans et al. [35] in an oxidation model for APS coatings.

\subsubsection{High temperature oxidation}

During the isothermal and thermal cycling oxidation tests, the Al content of the coating decreased through oxidation and inward diffusion. The surface $\mathrm{Al}$ consumption promoted the growth of a single phase $\gamma$ zone below the protective scale. This $\gamma$ zone is termed the outer $\beta$-depleted zone (OBDZ). The inner Al loss due to coating-substrate interdiffusion similarly caused the formation of an inner $\beta$ depleted zone (IBDZ). The zone where the $\beta$ phase still remained will be referred to as the $\beta$-left zone (BLZ). These zones are displayed in Fig. 4(a) for a specimen oxidized isothermally for $100 \mathrm{~h}$ at 1100 ${ }^{\circ} \mathrm{C}$.

The complete loss of the $\beta$-phase will render the coating non-protective; therefore, the lifetime of the coating can be predicted by modeling the time to total $\beta$ depletion $[5,15,17]$. With increasing oxidation time, the size of the OBDZ and IBDZ increased whereas the BLZ decreased, see Fig. 4(b), (c) and (d) where the thickness of the three zones are plotted as a function of oxidation time. The thickening rates of the OBDZ for the different oxidation conditions followed the order: TCF- $1100{ }^{\circ} \mathrm{C}$ $>$ iso- $1100{ }^{\circ} \mathrm{C}>$ iso- $1000{ }^{\circ} \mathrm{C}>$ iso- $900{ }^{\circ} \mathrm{C}$; while, for the IBDZ, the order was: TCF- $1100{ }^{\circ} \mathrm{C} \approx$ iso$1100{ }^{\circ} \mathrm{C}>$ iso- $1000{ }^{\circ} \mathrm{C}>$ iso- $900{ }^{\circ} \mathrm{C}$. Due to the heavier alumina scale spallation the consuming rate of $\mathrm{Al}$ in cyclic condition is faster, causing higher thickening rate of OBDZ, than that in isothermal condition at $1100{ }^{\circ} \mathrm{C}$. The thickness of the BLZ, which is a measure of the remaining $\mathrm{Al}$ reservoir, is the most interesting parameter for predicting the life of the coating.

There was no large difference in the microstructure near the coating-substrate interface for the TCF-1100 ${ }^{\circ} \mathrm{C}$ and iso- $1100{ }^{\circ} \mathrm{C}$ specimens, see Fig. 5(a) and (b). Due to the inward Al diffusion, $\beta$ close to the substrate-coating interface was dissolved in the coating during the high-temperature exposure, resulting in the IBDZ. In the substrate, some $\beta$ particles were observed to form beneath the 
coating-substrate interface; such phenomenon could be observed in the TCF-1100 ${ }^{\circ} \mathrm{C}$, iso- $1100{ }^{\circ} \mathrm{C}$ and iso- $1000{ }^{\circ} \mathrm{C}$ specimens, see Fig. 5(a)-(c), but not in the iso- $900{ }^{\circ} \mathrm{C}$ specimen shown in Fig. 5 (d). The $\beta$ phase in the substrate disappeared when the $\beta$ phase in the coating had been completely consumed.

The small (Ti,Ta)-rich MC carbides remained throughout the $1100{ }^{\circ} \mathrm{C}$ exposure since they were thermodynamically stable at this temperature. According to the results of the phase equilibrium calculation, see Fig. 2(b), transformation of the carbides can occur through $\mathrm{MC} \rightarrow \mathrm{M}_{23} \mathrm{C}_{6}$ at or below $1000{ }^{\circ} \mathrm{C}$. EDS mapping, shown in Fig. 6, demonstrates the presence of $(\mathrm{Cr}, \mathrm{Mo})$-rich $\mathrm{M}_{23} \mathrm{C}_{6}$ in the iso$1000{ }^{\circ} \mathrm{C}$ sample. $\mathrm{M}_{23} \mathrm{C}_{6}$ carbides were mainly found in the substrate beneath the coating-substrate interface at grain boundaries; they had a small, blocky shape. The occurrence of smaller (Ti,Ta)-rich MC carbides was sparse at $900{ }^{\circ} \mathrm{C}$ as shown in Fig. 5(d), which can be ascribed to its lower stability at lower temperatures. In addition, an Al-poor area was detected in the substrate, see the Al mapping in Fig. 6, resulting in the formation of $\gamma^{\prime}$-free zone, see Fig. 5(c), beneath the original coating-substrate interface; the original coating-substrate interface can be identified by the voids.

The morphology of the oxide scales for several different oxidation conditions is shown in Fig. 7. During thermal cycling the scale formed and grew during the hot part of the cycle. Temperature transients caused some of the oxide scale to spall from the coating surface due to the thermal stresses introduced by the mismatch in thermal expansion coefficients between the oxide scale and the coating. The addition of $\mathrm{Y}$ can improve the adhesion of the oxide scale through several mechanisms, such as removing sulfur from the scale-coating interface [36] and through the formation of Y-rich pegs at the scale-coating interface [37]. In this study, however, Y- and Si-rich oxides were commonly detected at the surface of the scale, see Fig. 7(a), rather than at the scale-coating interface. They may have formed and grew during the initial, transient oxidation stage, or due to the outward diffusion of $\mathrm{Y}$ and $\mathrm{Si}$ through the oxide scale. The detachment of the scale from the coating, and through-scale cracking, found for TCF-1 $100{ }^{\circ} \mathrm{C}$, see Fig. 7(a), may be due to thermal stresses but could also have arisen during the sample preparation process after the oxidation testing. For isothermal oxidation, the scale thickness gradually increased without any significant spallation. Oxidation might occur along the splat interfaces in near-surface areas as shown in Fig. 7(b) and (c). At $1100{ }^{\circ} \mathrm{C}$, the high mobility of oxygen enabled the oxygen to penetrate a certain depth under the coating surface, forming firstly some internal 
alumina island and eventually a continuous alumina layer, see Fig. 7(b). Continuous alumina scales formed through such a mechanism was also reported by Giggins et al. [38]. Such internal oxidation was only observed in samples of iso- $1100{ }^{\circ} \mathrm{C}$ for $50 \mathrm{~h}$ and $100 \mathrm{~h}$ according to SEM observation. If the activity and diffusivity of $\mathrm{Al}$ in the coating are high enough, the alumina scale grows directly at the coating surface [39]. At $900{ }^{\circ} \mathrm{C}$, see Fig. 7(d), Cr-rich particles, which were probably $\sigma$ phase in accordance with the phase diagram in Fig. 9, appeared in the BLZ and also in the OBDZ beneath the oxide scale. The formation of $\sigma$ phase in the $\mathrm{OBDZ}$ was not detected in specimens oxidized at $1100{ }^{\circ} \mathrm{C}$ and $1000{ }^{\circ} \mathrm{C}$.

Fig. 8 shows three Ni-Cr-Al ternary phase diagrams for different temperatures established by using the Thermo-Calc software. In the phase diagrams, $0.6 \mathrm{wt} . \%$ of Si was added; the Co concentration was set as 3-4.5 wt.\% higher than the Cr concentration in accordance with the EDS composition profiles, also shown in Fig. 8. A small amount of Y should have insignificant influence on such thermodynamic calculations and was not considered due also to the lack of data for $\mathrm{Y}$ in the used thermodynamic database. The composition profiles for different temperatures, shown in Fig. 8, were averaged over 3-5 different areas near the coating surface and include the OBDZ and part of the BLZ. In the profiles, distance $=0$ was set at the OBDZ-BLZ interface with distance $>0$ for the OBDZ and distance $<0$ for the BLZ. As can be seen in Fig. 8, the composition changes rapidly at the transition between OBDZ and BLZ. So-called diffusion paths [40-42] are also shown in the phase diagrams in Fig. 8, which consist of several points fetched from the concentration profiles. The orange triangle (for Al-rich BLZ) and the large blue square (for Al-poor BLZ) represent the compositions far away from the BLZ-OBDZ interface, while the smaller squares in red are from the interface region between the BLZ and the OBDZ.

The diffusion paths for $1000{ }^{\circ} \mathrm{C}$, Fig. 8(b), and $900{ }^{\circ} \mathrm{C}$, in Fig. 8(c), show that the composition of the BLZ is in the $\beta$-containing field in the phase diagram while the composition of the OBDZ is located very close to a boundary between the $\beta$-containing field and a $\beta$-free field; this indicates that the $\gamma$ phase in the OBDZ was saturated in Al. It further indicates that the mobility of oxygen was relatively low at those two temperatures as the transport of $\mathrm{Al}$ from the $\mathrm{BLZ}$ to the surface was sufficient to cause $\mathrm{Al}$ saturation in the $\gamma$ phase. This was, however, not the case for oxidation at 1100 
${ }^{\circ} \mathrm{C}$. The higher oxygen mobility promoted internal oxidation of Al below the coating surface (see Fig. 7(b)). Furthermore, because of the relatively fast $\mathrm{Al}$ consumption through oxidation, the composition in the OBDZ near the coating surface became $\mathrm{Al}$ poorer, lying far from the boundary between the $\gamma+\beta$ and the $\gamma$ fields in the phase diagram, see Fig. 8(a). In other words, the rapid consumption of $\mathrm{Al}$ at coating surface resulted in a composition gradient through the whole OBDZ, see profile in Fig. 8(a). In addition, at $900{ }^{\circ} \mathrm{C}$, the diffusion path is quite near the phase fields containing $\sigma$ phase; $\sigma$ phase is predicted to form in the BLZ, and in the OBDZ, which was indeed observed experimentally, (i.e. the Cr-rich particles in Fig. 7(d)).

The results above indicate that compositional evolution in the coating during oxidation is dependent on the thermodynamic behaviour of the coating. This makes it possible to use thermodynamic databases in design of alloy compositions of coatings for oxidation protection.

\subsection{Modeling results}

Before the actual oxidation-diffusion modeling, all available homogenization models in the DICTRA software were tested by considering coating-substrate interdiffusion only (i.e. no diffusion blocking or oxidation). In the MOBNI2 database used for the DICTRA simulation, the mobility data of alloying elements in $\gamma, \gamma^{\prime}$ and $\beta$ have been greatly improved [26]. Fig. 9 shows the calculated concentration profiles for $\mathrm{Ni}, \mathrm{Cr}$, $\mathrm{Co}$ and $\mathrm{Al}$ corresponding to $50 \mathrm{~h}$ at $1100{ }^{\circ} \mathrm{C}$; experimental data (points) are included for comparison. In the "Hashin-Strikman bounds" [43] the geometry of the phases are interpreted as concentric spherical shells. The "lower Hashin-Strikman bound" puts the phase with most sluggish kinetics onto outermost shell and vice versa for the "upper Hashin-Strikman bound". The model testing results in Fig. 9 show the too slow or too fast prediction by using "lower Hashin-Strikman bound" (Fig. (a)) or "upper Hashin-Strikman bound" (Fig. (b)). The "rule of mixture" model, which geometrically interprets the phases as continuous layers paralleled with the diffusion direction, gives good prediction on composition profiles according to the results in Fig. 9(c). By taking the majority phase as the matrix phase also including $\sigma$ as a none-diffusing phase, the 
composition profiles were calculated as shown in Fig. 9(d) showing a good agreement with the measured results but were easier to produce some unexpected noise on the curve. By an overall consideration the "rule of mixture" was the best choice and was applied for the following oxidationdiffusion modeling.

The oxidation-diffusion modeling combines surface oxidation, coating-substrate interdiffusion and microstructure-induced diffusion blocking. The measured oxide scale thicknesses for the different temperatures are shown in Fig. 10(a); curves were fitted by assuming parabolic oxidation kinetics. Fig. 10(b) gives the "interface blocking fractions" of the specimens, which are the occupied fraction of voids and/or oxides along the coating-substrate interface. The voids grew with thermal exposure; more so at higher temperature. The growth of the voids should be due to the Kirkendall effect. The increase in interface blocking fraction with time indicates that a time dependent diffusion blocking factor $P_{2}$ should perhaps have been used during the simulation; however, only constant values of $P_{1}$ and $P_{2}$ were used during the oxidation-diffusion modeling.

During modeling, thermodynamic results can easily be output from DICTRA. Fig. 11(a) shows the phase profiles for iso- $1100{ }^{\circ} \mathrm{C}$ for $50 \mathrm{~h}$ with no diffusion blocking (i.e. $P_{l}=0, P_{2}=0$ ). The formation of an OBDZ and an IBDZ, predicted by the simulation, agreed with experimental observations, see Fig. 6(a). The calculated $\gamma^{\prime}$ peak in the substrate, and the $\gamma^{\prime}$-free zone beneath the coating-substrate interface, were also in accordance with the observed microstructure, see Fig. 5 and 6. It is worth noting that several factors influence the simulation results: 1) imperfect oxidation law for $\mathrm{Al}, 2$ ) neglecting oxidation of elements other than $\mathrm{Al}, 3$ ) not considering the local volume change of the material due to, for instance, local phase transformations, 4) imperfection of the thermodynamic database and 5) varying deposition factors related to spraying conditions.

For lifetime predictions of coatings, the consumption rate of the $\beta$ phase in the coating is critical. Fig. 11(b) shows the experimentally measured BLZ thickness for iso- $1100{ }^{\circ} \mathrm{C}$ and results from modeling using different diffusion blocking parameters $P_{1}$ and $P_{2}$. Without diffusion blocking $\left(P_{l}=0\right.$, $P_{2}=0$ ), the calculated $\beta$ phase consumption occurred too fast compared to the experimental results (especially for $100 \mathrm{~h}$ ). Increasing $P_{1}$ and $P_{2}$ increased the diffusion blocking effect. As seen in Fig. 11 (b) for iso- $1100{ }^{\circ} \mathrm{C}$ condition, $P_{1}=0.5$ and $P_{2}=0.55$ gives the best agreement with experimental 
data. Composition profiles calculated for $P_{1}=0.5$ and $P_{2}=0.55$ are shown in Fig. 12. Compared to the results obtained without considering oxidation and diffusion blocking (i.e. Fig. 9(c)), a somewhat mismatching between the calculated and the measured compositions was found near the interface (Fig. 12). Such mismatch developed inevitably due to the separated programing of the substrate and coating parts in the oxidation-diffusion model. Besides that, a satisfactory agreement between the predicted results and experimental data was obtained.

The consumption of $\mathrm{Al}$ due to surface oxidation promoted the formation of an OBDZ with an $\mathrm{Al}$ concentration of $~ 3.8$ wt.\% near the surface, see the Al profile in Fig. 12. Both the calculated and measured $\mathrm{Al}$ profiles in the coating showed that the $\mathrm{Al}$ concentration in the BLZ decreased with time. $\mathrm{Al}$ diffusing into the substrate produced an $\mathrm{Al}$ peak near the interface, which increased the fraction of $\gamma^{\prime}$, causing a $\gamma^{\prime}$ peak as shown in Fig. 11(a); a $\gamma^{\prime}$-free zone in the substrate was also predicted by the model, see Fig. 11(a), as well as observed experimentally, see Fig. 5. The direction of diffusion depends on the activity gradient; Ni tended to diffuse from the substrate to the coating while Co and $\mathrm{Cr}$ diffused in the opposite direction. The predicted diffusion behaviour of $\mathrm{Ti}$ and $\mathrm{Si}$ also looks promising, see Fig. 12, while the calculated diffusion behaviour of heavy elements, i.e. Ta, Mo and W, seems to be too sluggish.

The simulated composition profiles for iso- $900{ }^{\circ} \mathrm{C}$ for $5000 \mathrm{~h}$, achieved by oxidation-diffusion modeling, are shown in Fig. 13. The composition profiles predicted by the model show a certain of mismatch with that from experimental values, especially in the regions near the coating-substrate interface. Such imperfect results are probably caused by either limitation of the database used in simulation or the imperfection of the model. Even though, the profiles of the main elements (i.e. Ni, $\mathrm{Co}, \mathrm{Cr}$ and $\mathrm{Al}$ ) are well predicted in the BLZ, indicating that a BLZ-based life prediction can still be used at lower temperatures. In Fig. 13 one interesting result predicted by the model is an increase of $\mathrm{Cr}$ concentration and, simultaneously a decrease of $\mathrm{Ni}$ and $\mathrm{Al}$ concentration, near the coating surface, indicating that some $\mathrm{Cr}$-rich phases form there. Actually, some $\mathrm{Cr}$-rich $\sigma$ phases were indeed observed in the microstructure, see Fig. 7(d).

By using the BLZ as an indicator for chemical degradation of the coating, the life of the coating at different temperatures can be predicted. This is shown in Fig. 14. The predicted lives of the coating, 
by simulation with $P_{1}=0.5$ and $P_{2}=0.55$, for iso- $1100{ }^{\circ} \mathrm{C}$, iso- $1000{ }^{\circ} \mathrm{C}$ and iso- $900{ }^{\circ} \mathrm{C}$ are $300 \mathrm{~h}$, $3000 \mathrm{~h}$ and $>10000 \mathrm{~h}$, respectively. At $1100{ }^{\circ} \mathrm{C}$ the simulation shows good agreement with experimental measurement. However at lower temperatures $\left(900{ }^{\circ} \mathrm{C}\right.$ and $\left.1000{ }^{\circ} \mathrm{C}\right)$ the $\beta$ depletion rate is overestimated compared with the long-time experimental data, indicating that larger diffusion blocking parameters should be used for these two temperatures; as suggested by the results in Fig.10(b), the blocking parameters may also have to be time-dependent. To improve the accuracy of the simulation, more experiments, especially testing for longer times at low temperatures (i.e. $1000{ }^{\circ} \mathrm{C}$, $900{ }^{\circ} \mathrm{C}$ ), are needed. In the future, such oxidation-diffusion model with diffusion blocking effect will be used to predict the life of other HVOF-deposited Ni-/Co-based MCrAlY coatings and APS coatings where there are more diffusion blocking structures caused by large oxide stringers.

\section{Conclusions}

In this study, the oxidation behaviour of an HVOF CoNiCrAlYSi coating on an IN792 substrate was studied for both isothermal oxidation and thermal cycling. The results from microstructural studies of the MCrAlY coating show that the Al-rich $\beta$ phase was gradually consumed due to surface oxidation and coating-substrate interdiffusion. The diffusion paths in the phase diagrams indicate that the composition in the outer $\beta$-depleted zone and oxide-forming behaviour at surface was influenced by the thermodynamic behaviour of the coating.

An oxidation-diffusion based life prediction model was developed. The influence of several phenomena was included: surface oxidation, coating-substrate interdiffusion and diffusion blocking. The composition profiles obtained from modeling show good agreement with experimental data. The depletion of Al-rich $\beta$ phase in the coating was taken to reflect the degradation of coating in high temperature oxidation, which was also well predicted by the model. The model shows promising results and is thought to be usable also for longer oxidation times and for APS coatings if further developed. 


\section{Acknowledgements}

Siemens Industrial Turbomachinery AB (Finspång, Sweden) and Swedish Energy Agency through KME consortium - ELFORSK are greatly acknowledged for their financial support in this study. Siemens Industrial Turbomachinery $\mathrm{AB}$ also supplied the materials and performed all oxidation and TCF tests. The GKN Aerospace Engine Systems is also acknowledged for its support in this research.

\section{References}

[1] J.T. DeMasi-Marcin and D.K. Gupta, Surf.Coat.Technol.(Switzerland) 68/69 (1994) 1.

[2] G.R. Wallwork and A.Z. Hed, Oxid. Met. 3 (2) (1971) 171.

[3] H.E. Evans and M.P. Taylor, Proceedings of the Institution of Mechanical Engineers G, Journal of Aerospace Engineering 220 (G1) (2006) 1.

[4] M.J. Pomeroy, Mater. Des. 26 (3) (2005) 223.

[5] M.P. Taylor, W.M. Pragnell, H.E. Evans, Mater. Sci. Forum 461-464 (2004) 239.

[6] R. Anton, J. Birkner, N. Czech, W. Stamm, Trans Tech Publications Ltd., Materials Science Forum (Switzerland) 369-372 (2000) 719.

[7] G.W. Goward, Surf. Coat. Technol. 108-109 (1-3) (1998) 73.

[8] N. Czech, F. Schmitz, W. Stamm, Mater.Manuf.Process.(USA) 10 (5) (1995) 1021.

[9] B. Gudmundsson and B.E. Jacobson, Thin Solid Films 173 (1) (1989) 99.

[10] P. Richer, M. Yandouzi, L. Beauvais, B. Jodoin, Surf. Coat. Technol. 204 (24) (2010) 3962.

[11] M. Di Ferdinando, A. Fossati, A. Lavacchi, U. Bardi, F. Borgioli, C. Borri, C. Giolli, A. Scrivani, Surf. Coat. Technol. 204 (15) (2010) 2499.

[12] J.A. Nesbitt and R.W. Heckel, Thin Solid Films 119 (3) (1984) 281.

[13] W.G. Sloof and T.J. Nijdam, Int. J. Mater. Rsych. 100 (10) (2009) 1318.

[14] D.R.G. Achar, R. Munoz-Arroyo, L. Singheiser, W.J. Quadakkers, Surf. Coat. Technol. 187 (2-3) (2004) 272.

[15] E.Y. Lee, D.M. Chartier, R.R. Biederman, R.D.J. Sisson, Surf. Coat. Technol. 32 (1-4) (1987) 19. 
[16] T. Beck, M. Biaas, P. Bednarz, L. Singheiser, K. Bobzin, N. Bagcivan, D. Parkot, T. Kashko, J. Petkovic, B. Hallstedt, S. Nemna, S.M. Jochen, Adv. Eng. Mater. 12 (3) (2010) 110.

[17] D. Renusch, M. Schorr, M. Schutze, Materials and Corrosion 59 (7) (2008) 547.

[18] T.J. Nijdam, L.P.H. Jeurgens, W.G. Sloof, Acta Materialia 51 (18) (2003) 5295.

[19] J.A. Nesbitt and R.W. Heckel, Metall.Trans.A 18A (12) (1987) 2087.

[20] T.J. Nijdam and W.G. Sloof, Acta Materialia 56 (18) (2008) 4972.

[21] J. Hald, L. Korcakova, H.K. Danielsen, K.V. Dahl, Materials Science and Technology 24 (2) (2008) 149.

[22] B. Sundman, B. Jansson, J. Andersson, Calphad 9 (2) (1985) 153.

[23] J. Agren, Journal of Physics and Chemistry of Solids 43 (4) (1982) 385.

[24] H. Larsson and A. Engström, Acta Materialia 54 (9) (2006) 2431.

[25] J.M. Larson, Metall.Trans.A 7A (10) (1976) 1497.

[26] Thermo-Calc Software AB, (2011)

[27] R.C. Reed, The Superalloys Fundamentals and Applications, Cambridge, 2006.

[28] C.T. Sims, N.S. Stoloff, W.C. Hagel, xx + 615, 16 x $23 \mathrm{~cm}$, Illustrated, pounds sterling 63.75 (1987)

[29] J.R. Davis, Heat-Resistant Materials, ASM International, Member/Customer Service Center, Materials Park, OH 44073-0002, USA, 1997.

[30] P. Puetz, X. Huang, R.S. Lima, Q. Yang, L. Zhao, Surf. Coat. Tech. 205 (2) (2010) 647.

[31] D. Toma, W. Brandl, U. Köster, Surf. Coat. Technol. 120-121 (1999) 8.

[32] W. Brandl, D. Toma, H.J. Grabke, Surf. Coat. Technol. 108-109 (1-3) (1998) 10.

[33] J. Pablo and T. Alvarez, RWTH University (Thesis) (2008)

[34] A. Fossati, M. Di Ferdinando, A. Lavacchi, U. Bardi, C. Giolli, A. Scrivani, Surface and Coatings Technology 204 (21-22) (2010) 3723.

[35] H.E. Evans and M.P. Taylor, Oxidation of Metals (USA) 55 (1-2) (2001) 17.

[36] J.G. Smeggil, Mater. Sci. Eng. 87 (1987) 261.

[37] J.K. Tien and F.S. Pettit, Metall. Mater. Tran. B 3 (1972) 1587.

[38] C.S. Giggins and F.S. Pettit, J. Electrochem. Soc. 118 (11) (1971) 1782.

[39] F.H. Stott, G.C. Wood, M.G. Hobby, OXID METALS 3 (2) (1971) 103. 
[40] J.E. Morral, C. Jin, A. Engstr, J. Ågren, Scr. Mater. 34 (11) (1996) 1661.

[41] T. Gomez-Acebo, B. Navarcorena, F. Castro, Journal of Phase Equilibria and Diffusion 25 (3) (2004) 237.

[42] A. Engstrom, J.E. Morral, J. Agren, Acta Materialia (USA) 45 (3) (1997) 1189.

[43] Z. Hashin and S. Shtrikman, Journal of Applied Physics 33 (10) (1962) 3125. 
Table 1. Nominal compositions in wt.\% of the substrate IN792 and the CoNiCrAlYSi coating.

\begin{tabular}{cccccccccccccc}
\hline Alloys & $\mathrm{Ni}$ & $\mathrm{Cr}$ & $\mathrm{Co}$ & $\mathrm{W}$ & $\mathrm{Ta}$ & $\mathrm{Ti}$ & $\mathrm{Al}$ & $\mathrm{Mo}$ & $\mathrm{Y}$ & $\mathrm{Si}$ & $\mathrm{C}$ & $\mathrm{Zr}$ & $\mathrm{B}$ \\
\hline IN792 & Bal. & 12.5 & 9.0 & 4.175 & 4.175 & 3.975 & 3.375 & 1.9 & - & - & 0.08 & 0.0175 & 0.015 \\
CoNiCrAlYSi & 30 & 28 & Bal. & - & - & - & 7.5 & - & 0.6 & 0.6 & - & - & - \\
\hline
\end{tabular}


Table 2. Performed oxidation testing.

\begin{tabular}{lllll}
\hline Condition & TCF- $1100{ }^{\circ} \mathrm{C}$, cycles & iso- $1100{ }^{\circ} \mathrm{C}, \mathrm{h}$ & iso- $1000{ }^{\circ} \mathrm{C}, \mathrm{h}$ & iso- $-900{ }^{\circ} \mathrm{C}, \mathrm{h}$ \\
\hline Time & 50 & 50 & 100 & 500 \\
& 100 & 100 & 500 & 1500 \\
& 300 & 300 & 1000 & 2783 \\
& 500 & 500 & 1500 & 5000 \\
\hline
\end{tabular}



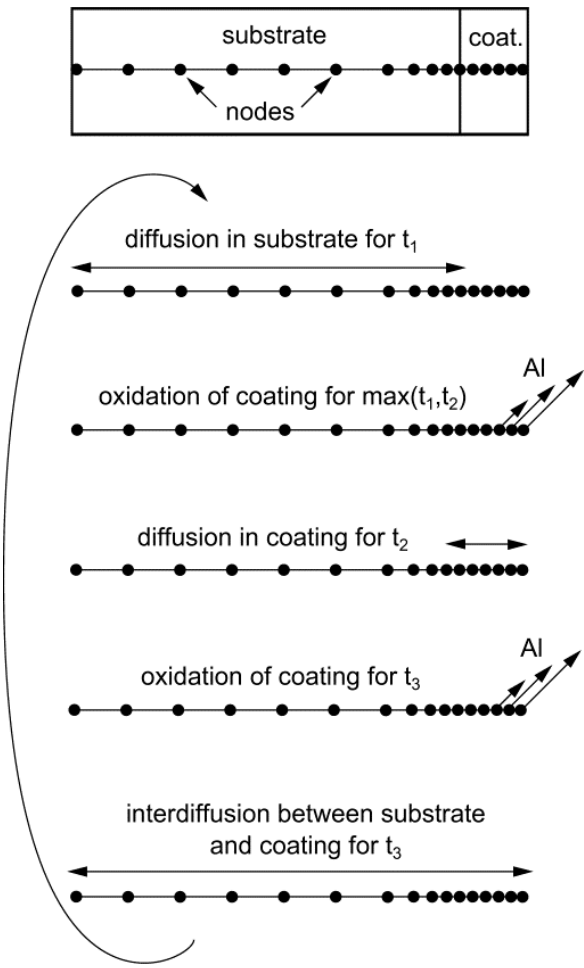

Figure 1 . The oxidation-diffusion simulation schematically outlined. The thicknesses of the substrate and the coating in the simulation were $800 \mu \mathrm{m}$ and $200 \mu \mathrm{m}$, respectively. 

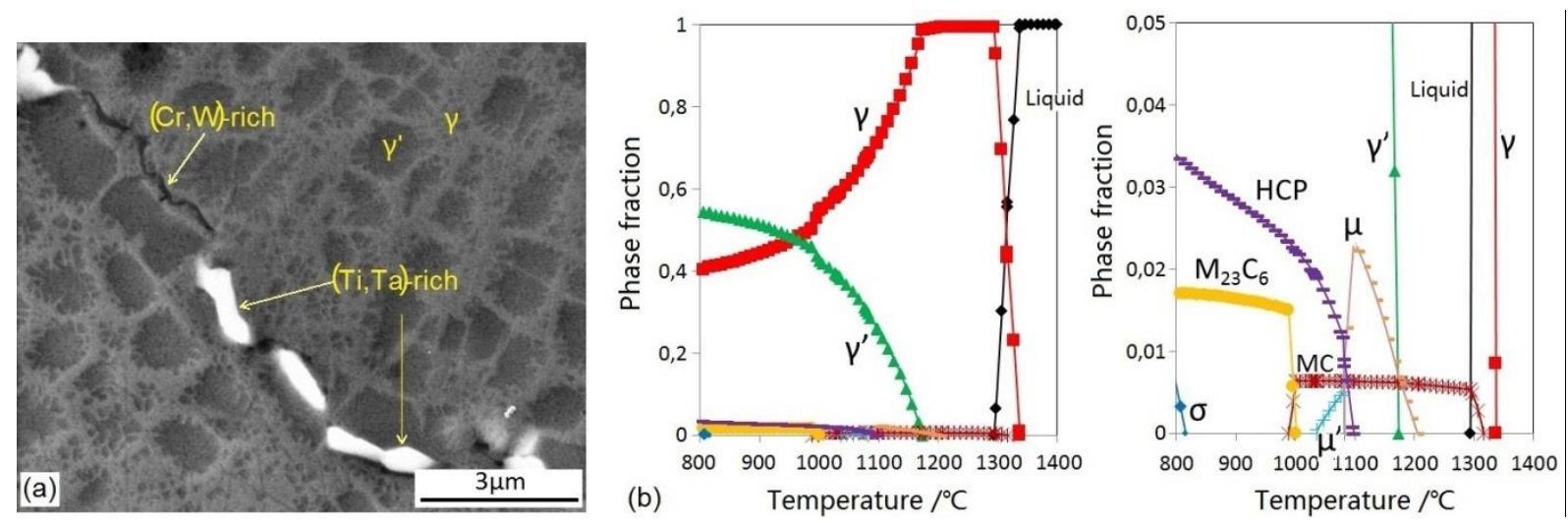

Figure 2. Microstructure in cast superalloy IN792 after heat treatment: (a) SE image showing $\gamma-\gamma^{\prime}$ and carbides and (b) equilibrium calculation of the microstructure in IN792 by the Thermo-Calc software. 

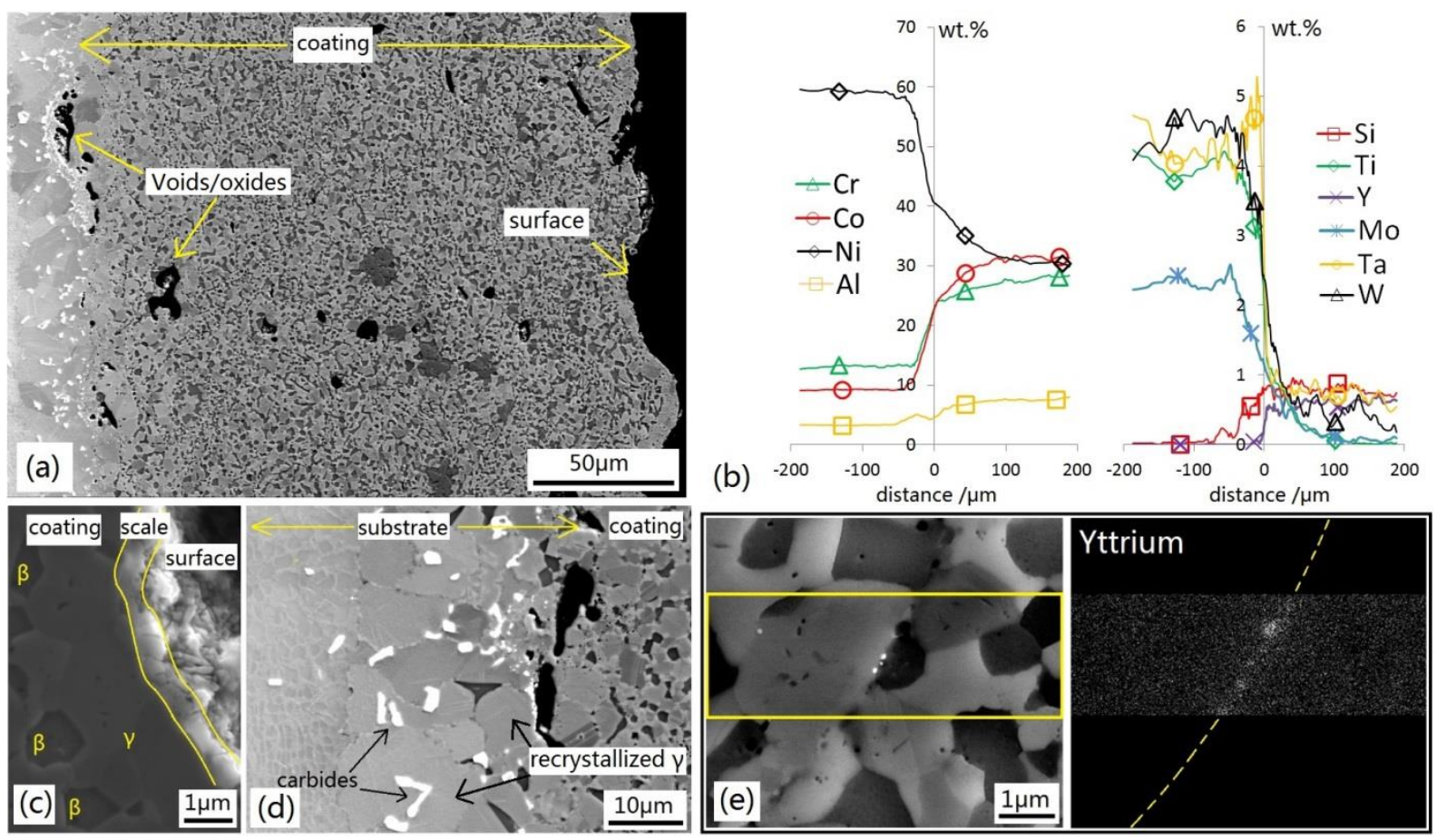

Figure 3. Specimen after solution and aging heat treatments: (a) overview of the coating microstructure (BSE image), (b) composition profile (averaged from several positions on the specimen), (c) microstructure near coating surface (SE image), (d) microstructure near coatingsubstrate interface (BSE image) and (e) microstructure (SE image) and EDS map of yttrium at splat interface in the coating. 

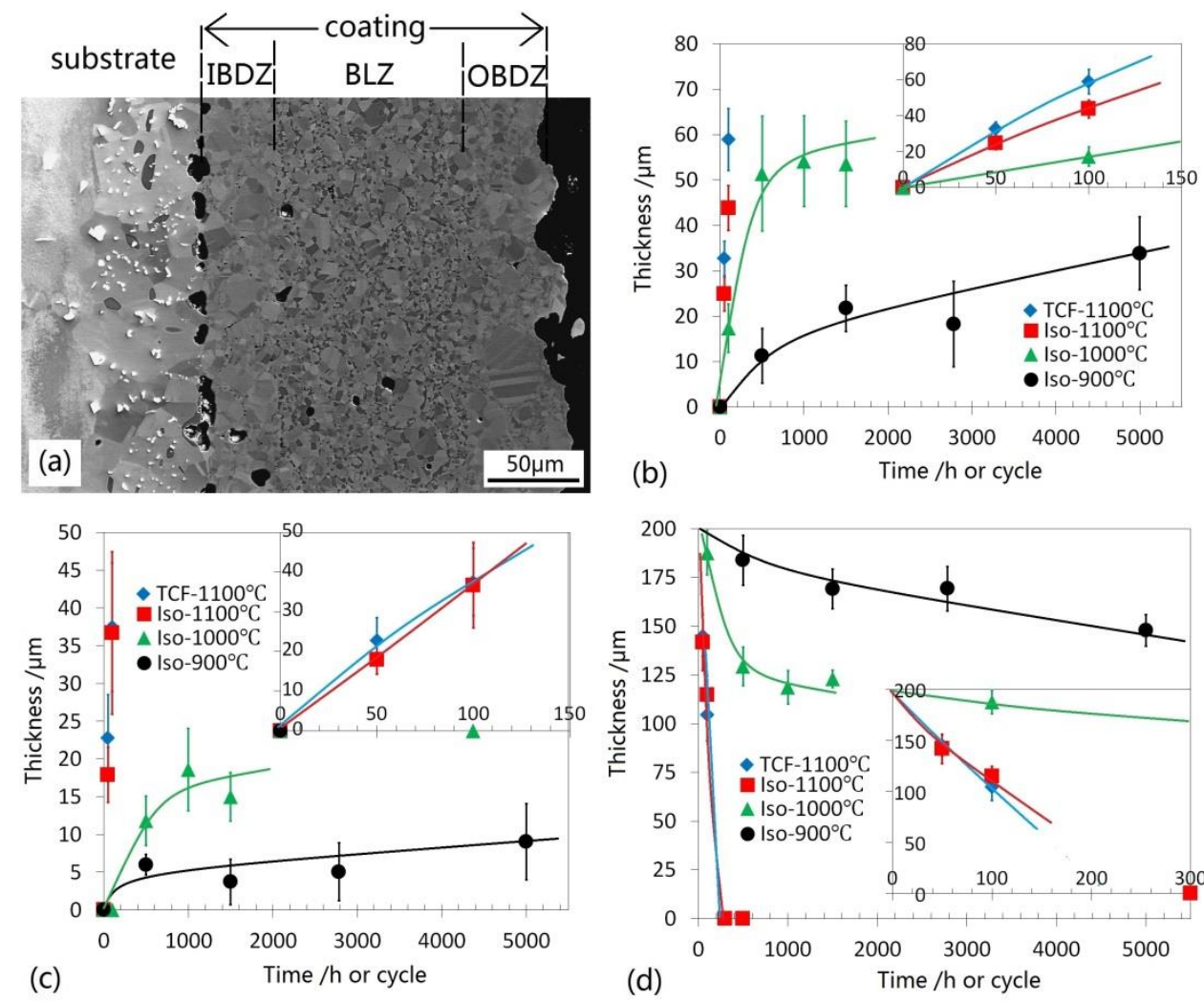

Figure 4. Results from the iso- $1100{ }^{\circ} \mathrm{C}$ specimen after $100 \mathrm{~h}$ : (a) microstructure of the coating (BSE image), (b) evolution of the outer- $\beta$-depletion zone (OBDZ), (c) evolution of inner- $\beta$-depletion zone (IBDZ) and (d) evolution of $\beta$-left zone (BLZ). The error bars (standard deviations) show the scatter from measurements at 10 random regions in the specimen. 

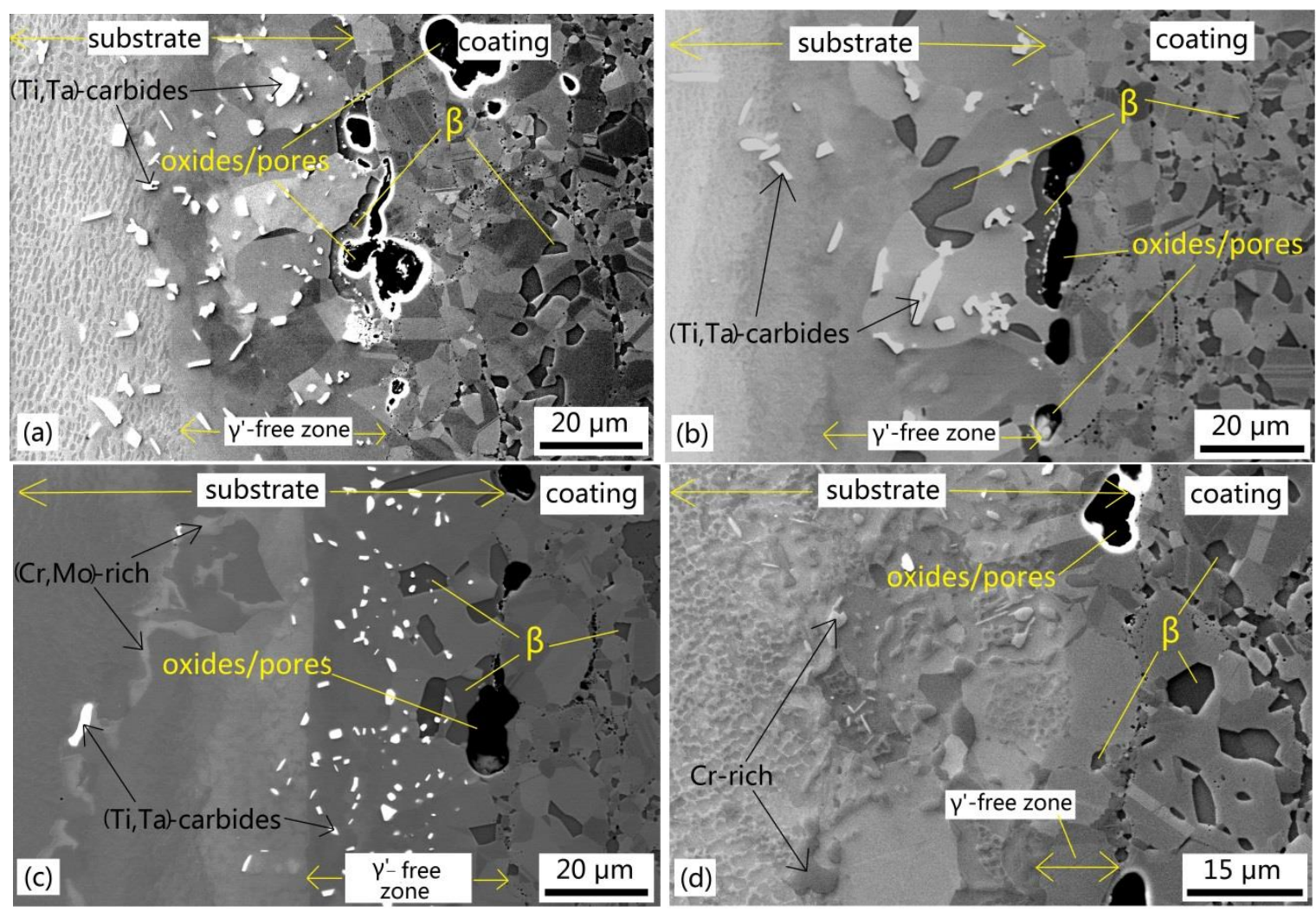

Figure 5. Microstructure near the coating-substrate interface for the following specimens: (a) TCF$1100{ }^{\circ} \mathrm{C}$ for 50 cycles (SE image), (b) iso- $1100{ }^{\circ} \mathrm{C}$ for $50 \mathrm{~h}$ (BSE image), (c) iso- $1000{ }^{\circ} \mathrm{C}$ for $1500 \mathrm{~h}$ (BSE image) and (d) iso- $900{ }^{\circ} \mathrm{C}$ for $5000 \mathrm{~h}$ (SE image). 

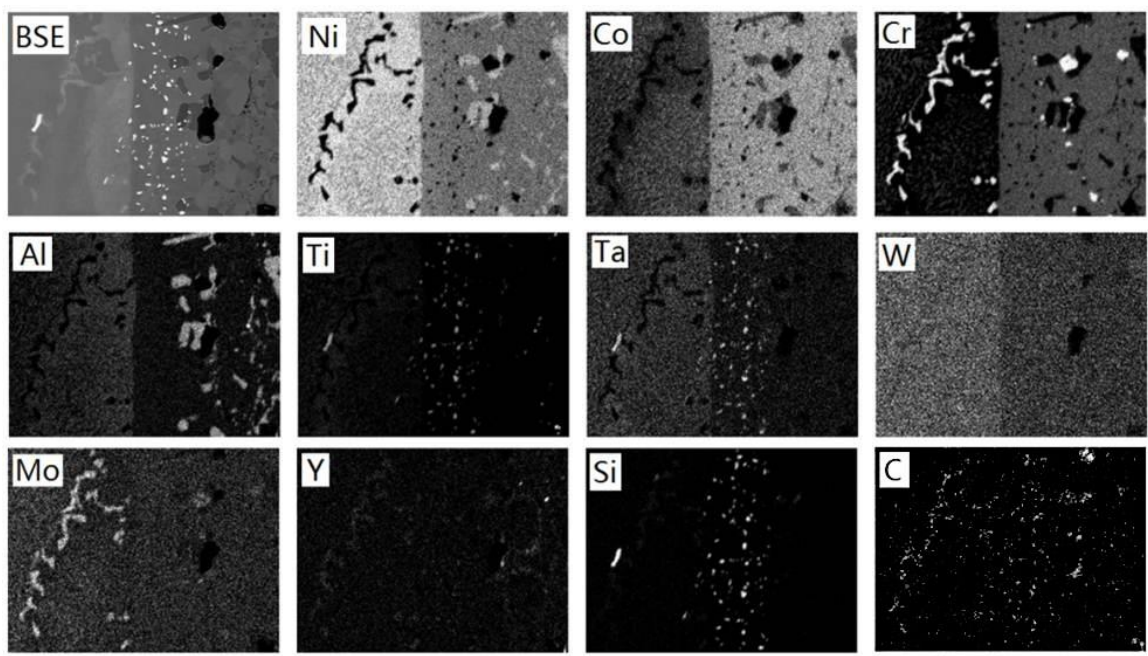

Figure 6. EDS mapping around coating/substrate interface of the specimen exposed to iso- $1000{ }^{\circ} \mathrm{C}$ for $1500 \mathrm{~h}$. 


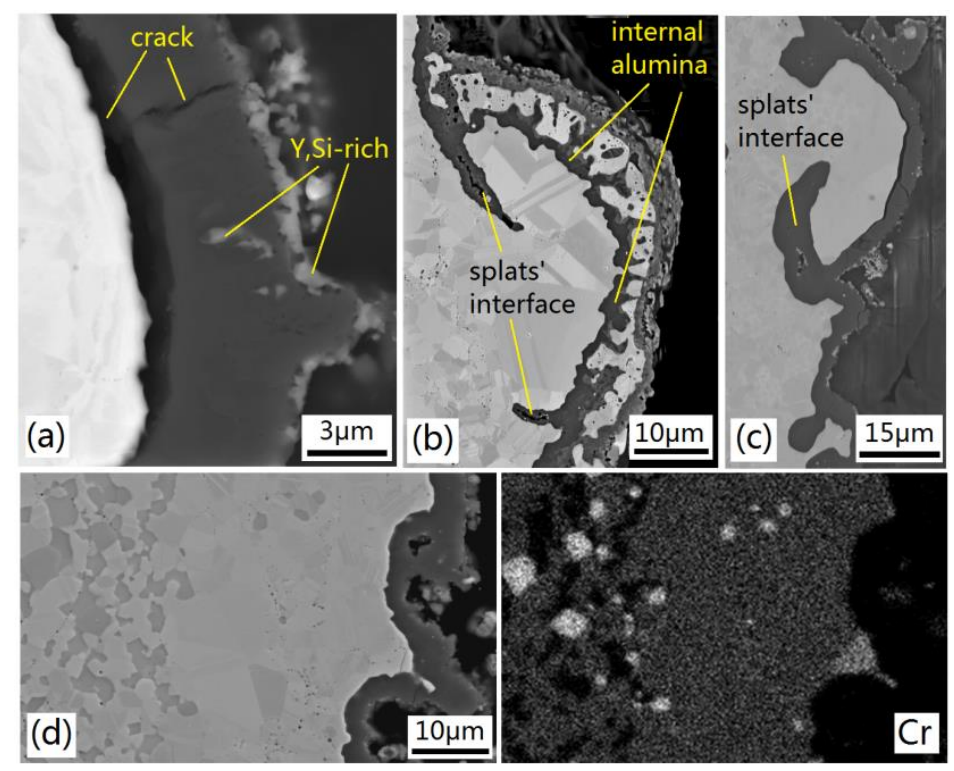

Figure 7. Oxide scale morphology for some different oxidation conditions: (a) TCF-1100 ${ }^{\circ} \mathrm{C}$ for 300 cycles (BSE image), (b) iso- $1100{ }^{\circ} \mathrm{C}$ for $50 \mathrm{~h}$ (BSE image), (c) iso- $1000{ }^{\circ} \mathrm{C}$ for $500 \mathrm{~h}$ (BSE image) and (d) iso- $900{ }^{\circ} \mathrm{C}$ for $5000 \mathrm{~h}$, BSE image and EDS map of $\mathrm{Cr}$. 


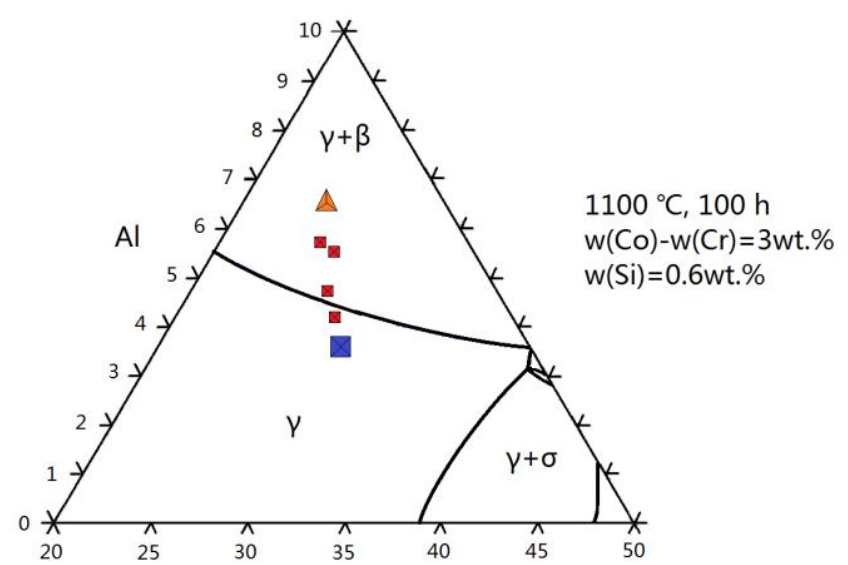

(a)

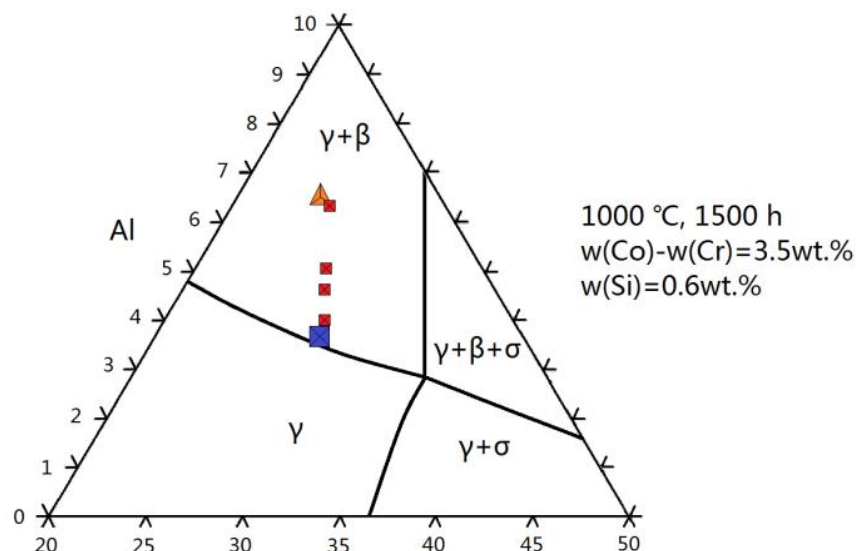

(b)

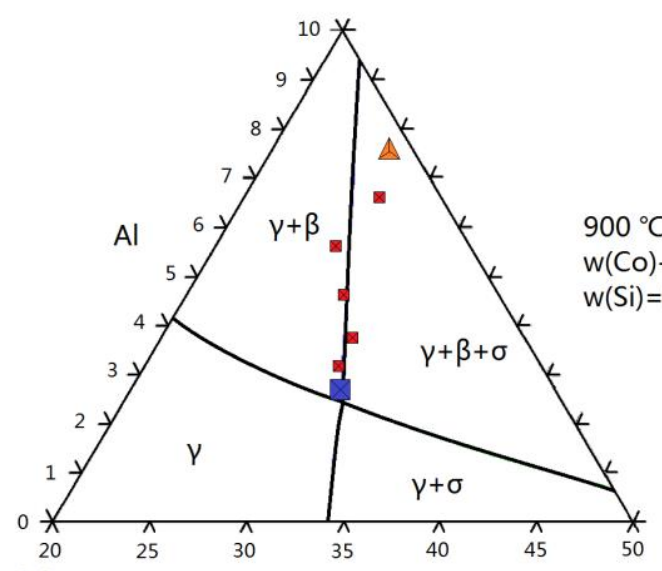

(c)

$\mathrm{Cr}$
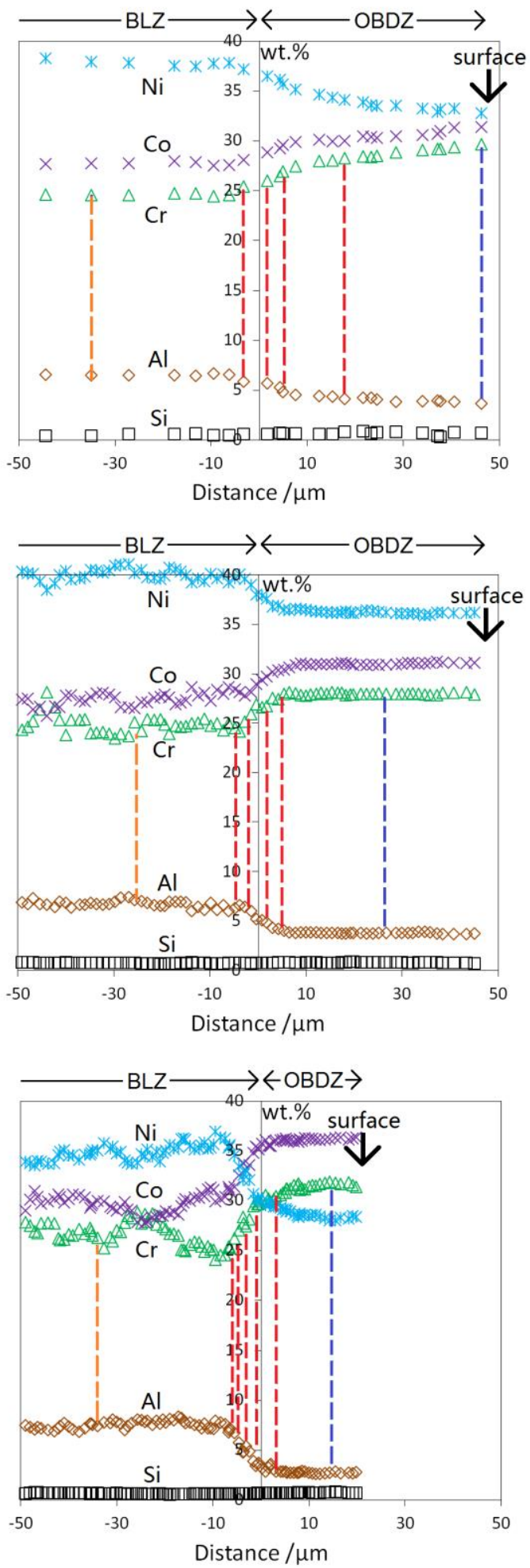

Figure 8. Diffusion paths in Ni-Cr-Al ternary phase diagrams obtained for the conditions shown beside the diagrams, for: (a) $1100{ }^{\circ} \mathrm{C}$, (b) $1000{ }^{\circ} \mathrm{C}$ and (c) $900{ }^{\circ} \mathrm{C}$. The composition points in the phase diagrams come from the compositions at the positions marked with colored vertical lines in the corresponding composition profiles. 

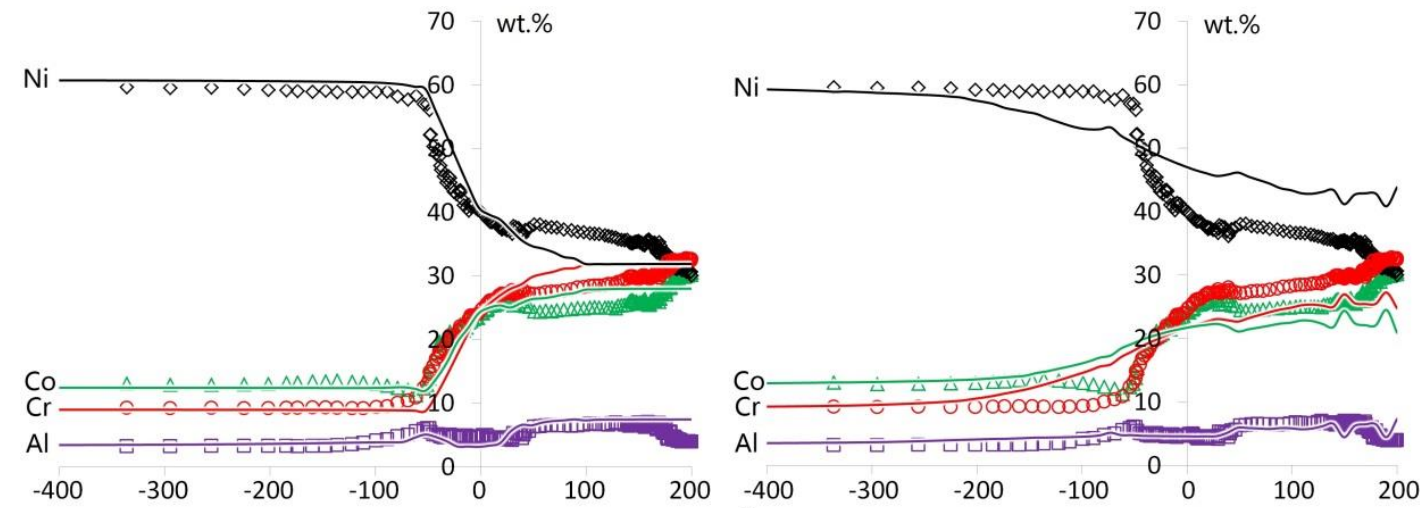

(a)

(b)
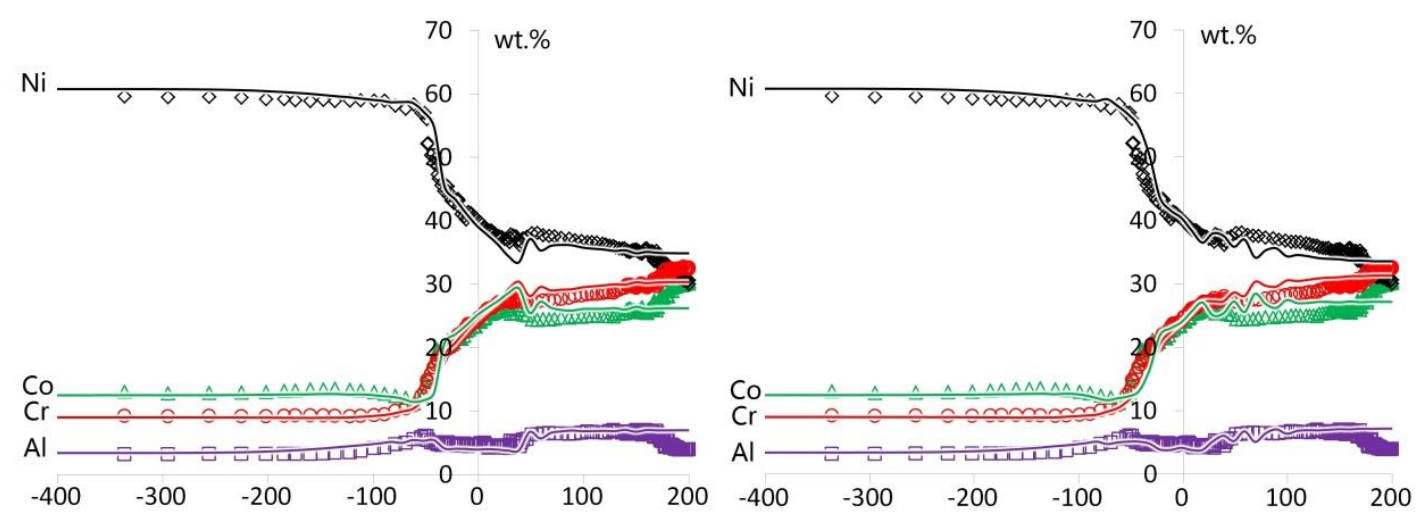

(c)

Distance $/ \mu \mathrm{m}$

(d)

Distance $/ \mu \mathrm{m}$

Figure 9. Composition profiles as predicted by different homogenization models: (a) lower HashinStrikman bound, (b) upper Hashin-Strikman bound, (c) rule of mixture and (d) Hashin-Shtrikman bound with the majority phase as matrix phase. Curves show simulation results and points are experimental data. 

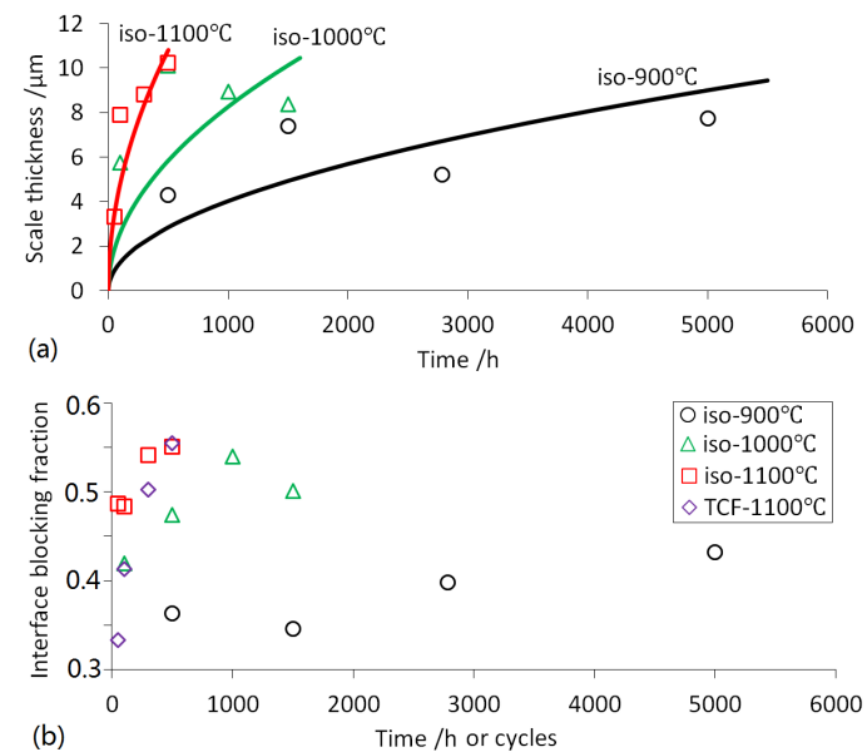

Figure 10. Oxide thickness and interface blocking as function of time at high temperature: (a) oxide scale thickness in isothermally oxidized specimens and (b) fraction of voids and oxides at the substrate-coating interface. 

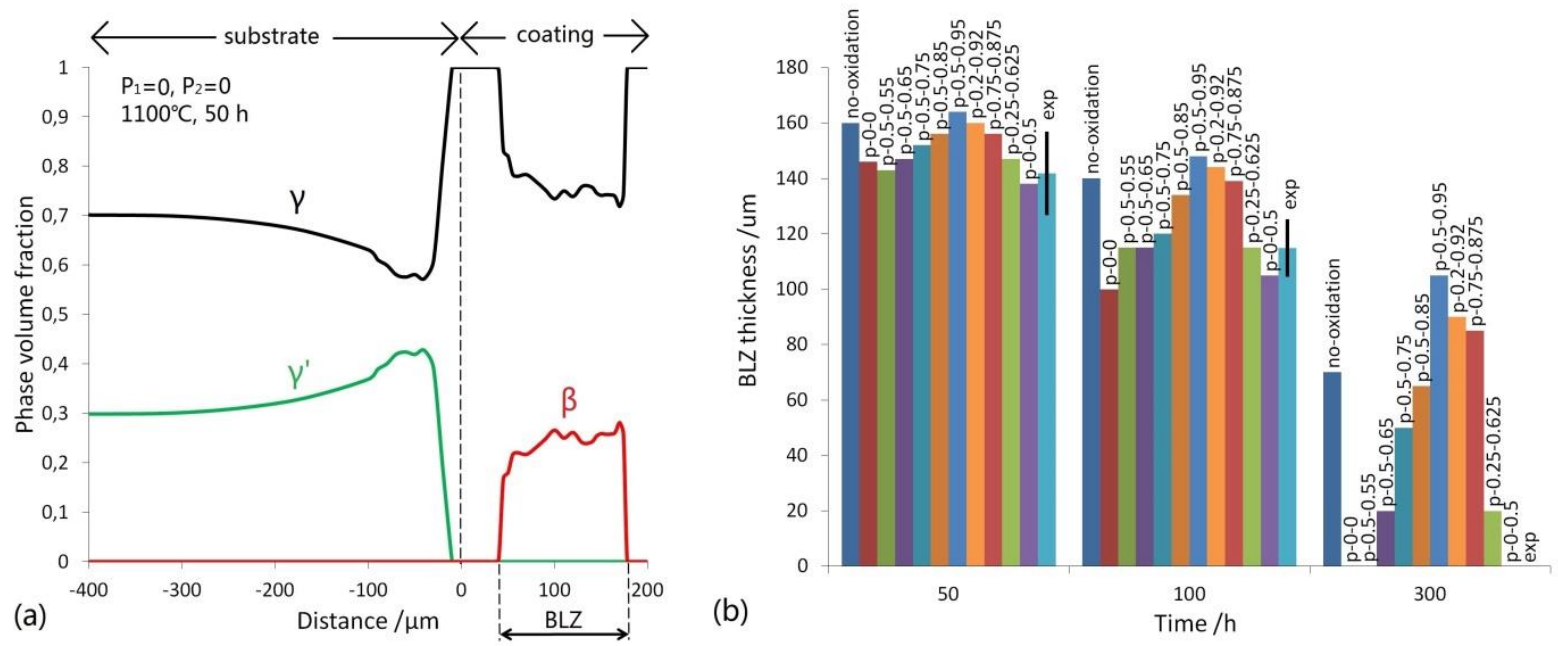

Figure 11. Results from simulations: (a) predicted phase profile for iso- $1100{ }^{\circ} \mathrm{C}$ for $50 \mathrm{~h}$ without diffusion blocking (i.e. $P_{1}=0, P_{2}=0$ ) and (b) the blocking parameter influence on the calculated BLZ thickness (for iso- $1100{ }^{\circ} \mathrm{C}$ ), blocking is given in the form "p- $P_{l}-P_{2}$ ". 

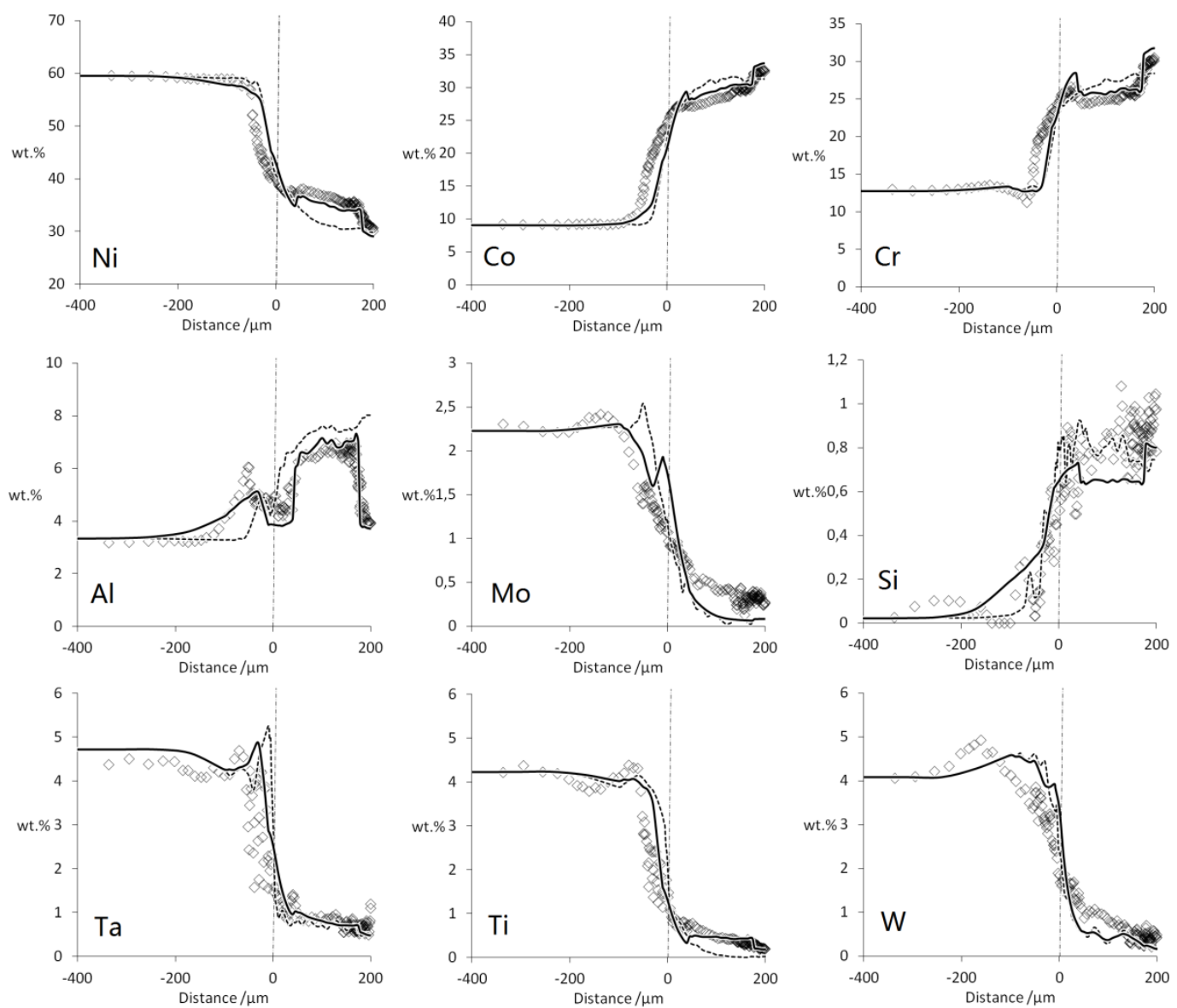

Figure 12. Composition profiles after $50 \mathrm{~h}$ at $1100{ }^{\circ} \mathrm{C}$ with the diffusion blocking $P_{l}=0.5, P_{2}=0.55$. Solid curves are simulation results and points are experimental results. Dashed curves are simulation input data from heat-treated specimens. Vertical dash lines mark the position of the interface between substrate (distance $<0$ ) and coating (distance $>0$ ). 

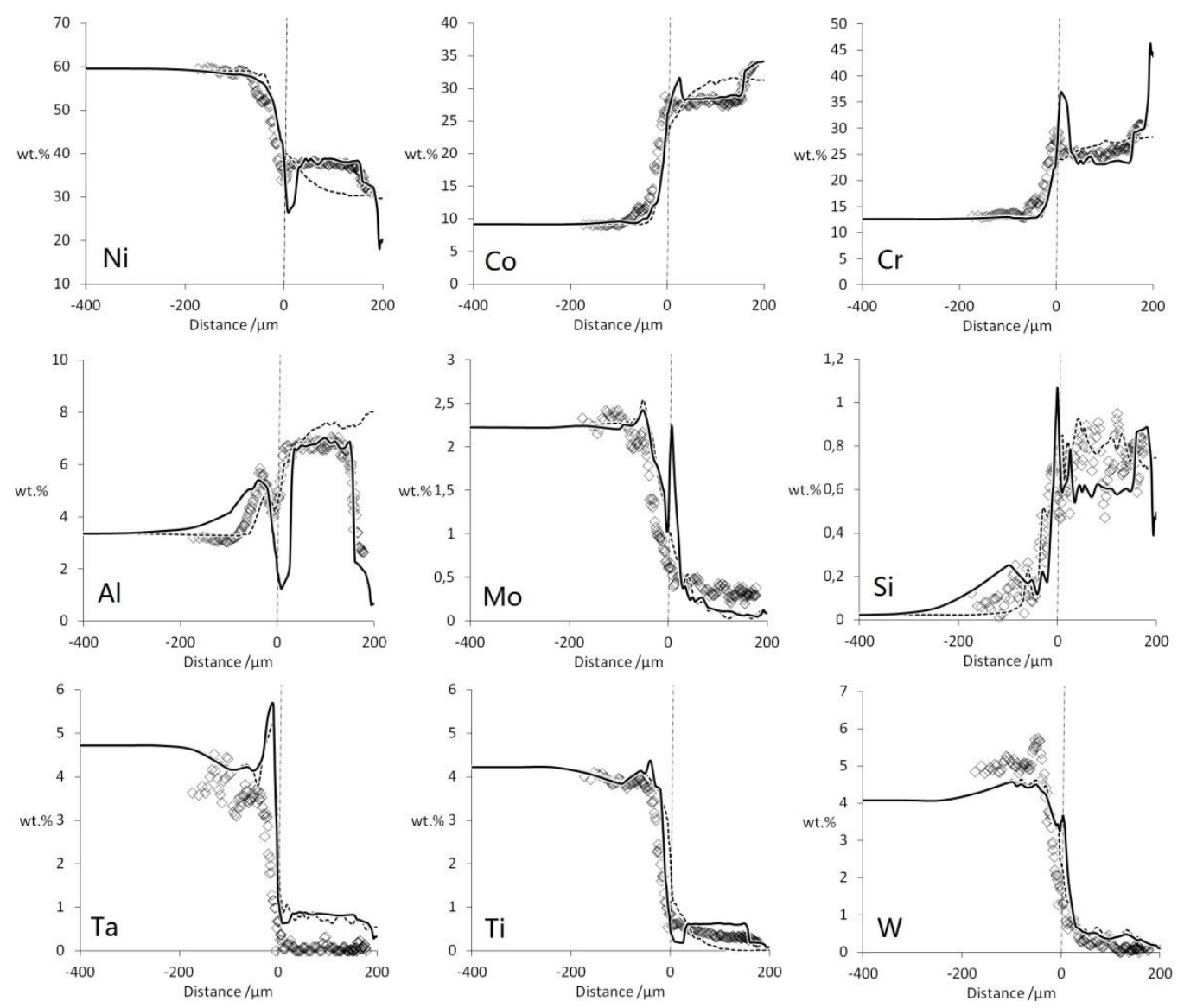

Figure 13. Composition profiles after $5000 \mathrm{~h}$ at $900{ }^{\circ} \mathrm{C}$ with the diffusion blocking $P_{1}=0.5, P_{2}=0.55$. Solid curves are simulation results and points are experimental results. Dashed curves are simulation input data from heat-treated specimens. Vertical dash lines mark the position of the interface between substrate (distance $<0$ ) and coating (distance $>0$ ). 


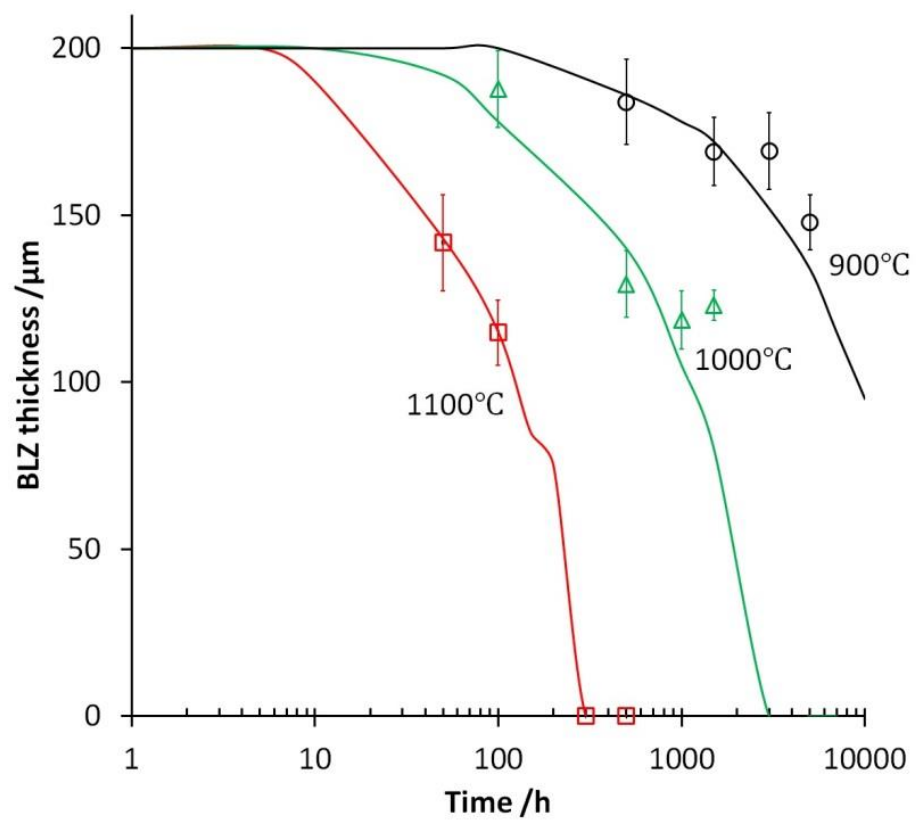

Figure 14. Predicted and measured BLZ thickness as function of time. The solid curves are simulated results using $P_{1}=0.5, P_{2}=0.55$ and the points are experimental results. 